\title{
Research on Risk Management and Profitability of Bike Sharing Business Model
}

\author{
Xiangyu Tian ${ }^{1, \dagger}$, Yijie Wang ${ }^{2, *, \dagger}$, Yuwen Shi ${ }^{3, \dagger}$ \\ ${ }^{1}$ Faculty of Vehicle Engineering and Mechanics, Dalian University of Technology, Dalian, 116081, China \\ ${ }^{2}$ Business School, The University of Liverpool, Liverpool, L693BX, U.K. \\ ${ }^{3}$ Business School, Sichuan University, Chengdu, 610064, China \\ ${ }^{*}$ Corresponding author. Email: psywa152@liverpool.ac.uk \\ ${ }^{t}$ These authors contributed equally.
}

\begin{abstract}
People's needs for personal leasing create the explosion of sharing economy systems, bike sharing meets people's demand for short-distance and eco-friendly travels. Therefore, many bike sharing enterprises emerge as the times require. In the context of bike sharing, risk management and profitability are vital factors that affect the survival and sustainable development of shared-bike enterprises. However, today, the profit model is unclear, and many profit issues occur in the whole bike sharing industry. This paper investigates and classifies potential causes of the lack of profitability of shared-bike enterprises and how companies can tackle those issues. Specifically, the literature analysis method and case study are used for the research. We propose the substance of bike sharing, which is the basic premise for profitability. Then, we analyze the deficiency of bike-sharing platforms and profits and costs of OFO, a typical example of a bike sharing failure. After which, management risks are segmented into financial risk, operational risk, credit risk, technical risk, and social risk and explained in further detail. We subsequently discuss feasible solutions to deal with problems at present and summarize them into five main categories of strategies: cost reduction, multiple profit methods, internal supervision system establishment, technical development, and social publicity. The paper provides effective suggestions for bike sharing risk management and profitability. It aims to offer a reference for shared-bike enterprises and other sharing economy organizations to maintain long-term and stable progress and development, contributing to the shared-bike business model and even the sharing economy systems.
\end{abstract}

Keywords: Bike sharing, Risk management, Profitability, Problems, Strategies.

\section{INTRODUCTION}

As the Internet and mobile technologies develop and people's needs for personal leasing increase and change, sharing economy systems are created to fulfill the public's requests, with bicycle sharing system becoming a representative form of it, where the process from membership, rental to return is automatic. Fanaee-T, Hadi, and Gama, Joao counted that currently, over 500 bicycle sharing programs are operating worldwide [1]. Shared Bikes have been used in more than 900 cities worldwide, and there are over 245 million active users in China till June 2018[2]. To cater to an eco-friendly lifestyle, bike-sharing has gradually come into people's sight, which is convenient for people to travel and conducive to the development of environmental transportation. The bike-sharing system has brought updated social value and opportunities to many countries and regions and has a significant impact on markets, industries, and business structures. However, the rapid development of bike-sharing has led to a series of enterprise risk problems. The risk management of bike-sharing enterprises is one of the most concerning problems at present. The common problems are that the cost of sharing-bikes is exorbitant, and there is no clear profit model. OFO, one of the biggest Chinese bikesharing companies, acquired more than 500 million dollars in its financing stage before March 2017. Still, it cannot figure out a proper way to operate the business and finally had to declare bankruptcy. For the sustainable development of bike-sharing enterprises, an effective profit model is indispensable, where risk management and profitability of bike-sharing are essential. 
Sharing economy was first presented by Fairson and Spans, after which the concept was supplemented by many scholars [3]. According to the summary from Zhu, and Liu, the sharing economy refers to the situation where the right to use idle resources of individuals or institutions transfers to others through a third-party platform for profits[4]. The owners gain payment by sharing resources, and lower prices are provided to customers to obtain goods and services, improving the utilization rate of goods. Bike-sharing firms need various pricing and availability strategies, also take the government subsidy policies into considerations. The availability of bike-sharing was defined as "the likelihood of finding an appropriately located unused bike" [5]. To increase the profitability of bike-sharing, many studies focused on re-balance the number of bikes and enlarge the scale of shared bikes [6-9]. However, the number of shared bikes has reached maximum affordability in target areas. Another way is to repair non-functioning shared bikes, which can also improve availability [6]. However, changing the number of bikes means more repairing in the future and repairing needs investment, so whether it is profitable in a long period is not clear. Chen discussed the effectiveness of the subsidy policy and argued that common bike-sharing firm decides to increase availability by promoting the cost of availability to optimize margins. In contrast, once the cost is relatively high, increasing subsidy may not necessarily improve the social welfare of bikesharing[10].

In today's era of network development, many scholars either through the network search or through social research. An in-depth study was conducted on shared cycling. Most of the researchers' study is about the social or personal effects of shared bikes and the development of shared bikes in the Covid-19 environment and response measures. Sharing a bike has both social and personal advantages. Through research, scholars have found that sharing a bike is beneficial to the environment and can reduce emissions. For individuals, it can play a fitness role. Cycling has great cardiovascular benefits and can effectively relieve depression and anxiety. Other scholars also have found that one of the disadvantages of shared bikes is vital to people's health and safety. The absence of helmet protection means that many cyclists are not protected in the event of a car accident. Scholars use only 20 percent of helmets on shared bikes, according to social research and large data. This significantly reduces the safety factor of cyclists. In the Covid-19 environment, scholars have found that shared bikes can take advantage of physical distances to address the risks. In the study, the researchers note that the Centers for Disease Control and Prevention recommends "minimizing close contact" with others in the event of an unsafe environment. For example, Shared bikes can control not only emissions, but also traffic at distances. They are providing users with healthy, low-impact exercise. Scholars have found that it through data analysis. Nineteen of the 20 U.S. cities have cut public transportation services. Thus, under the influence of covid-19, the shared bike has gradually become a popular way of travel. This mode of travel gradually replaces public transport, taxis. These must contact the mode of transport closely. Few scholars have studied risk management and profitability in the shared bike business model. Therefore, the riskprofit problem of sharing a bike will be the focus of this paper.

This paper explores the problem of high cost and low profit in risk management and profitability of shared bikes through literature research, case study, and comparative analysis. This problem may be affected by the small number of users or by the fact that the mode of travel of shared cycling has not become widespread. The solution to this problem can let the user submit a deposit first. This ensures that the user is compensated for the damage to the bike, both by using the tool and by the time the bike is damaged.

\section{METHODOLOGY}

\subsection{Literature Analysis Method}

The literature analysis methodology studies diverse and relevant literature to assess the existing intellectual territory and identify a research question to advance our knowledge [11]. First, the narrative literature review method helps to grasp the general knowledge on the development of sharing economy and narrow the research scope to sharing bicycles which are determined in terms of its theoretical gap and wide uncertainty. Second, the systematic review method is also used because it focuses on specific questions and refers to selecting and evaluating relative papers and then leading to appropriate results. Based on some preliminary literature searches, we find the novel nature of sharing bicycle business model and some features on this business model, such as the key resources of idle bikes and the key process of matching supply with demand punctually and precisely, which indeed pushes our research further. However, the systematic review method has some constraints, including the immature studying of existing research about sharing bicycles, which may cause biased results. Around sharing bicycle, many papers indicate its impacts, motivations, and other various aspects, but the papers on financial perspectives are not much and hence profitability is possibly a great viewpoint to analyze.

\subsection{Case Study}

The case study is investigating and analyzing the representative events in-depth and carefully[12]. In the paper, case studies also play a vital role in deciding the 
theme, which is explained partly by the failure of OFO. For example, the bankruptcy of OFO reflects the underlying problems of operating the sharing bicycle business, which brings about the doubt that sharing bicycles is only the lease of the firm's assets, not truly the sharing economy using other's assets, like DiDi. So it is meaningful to conclude the primary problems and risks of sharing bicycles by analyzing the profitability through cases.

Case studies in the paper are used with plenty of comparison skills. According to a certain standard, two or more related social phenomena are compared and analyzed to determine their similarities and differences. Then studying the reasons for the similarities and differences and explore their mutual influence and other relationships. First, to find the deficiency of sharing bicycles, we study and compare samples of leading firms in representative industries of sharing economy, including DiDi in the sharing ride sector and OFO in sharing bike sector. DiDi was founded in 2012 and became the largest platform in China's peer-to-peer sharing ride market. OFO is a younger online travel platform that was created to solve the problem of "the last kilometer" in a trip. Second, we introduce the story of Hellobike, another mobile travel platform providing shared travel solutions for the sustainable development of smart cities with the mission of "technology promotes travel evolution". Then we conduct comparisons between OFO and Hellobike, investigating the risky and influential factors on the development of sharing bicycle companies, like the cost structure.

\section{RESULT}

\subsection{Profitability Analysis}

\subsubsection{Substance of Sharing Bicycle}

In essence, bike-sharing is an "Internet plus" rental economy. Compared with the traditional bicycle rental, it has only one more app, improving the convenience for users to obtain bicycles, which is also the fundamental premise for understanding the success or failure of its business model. On the one hand, it solves the "last mile" problem of many office workers between their residence and the subway station so that the majority of users do not have to worry about the risk of traffic jams. On the other hand, it is convenient for tourists to travel, and they can ride between scenic spots with a short distance. Another key point is "low-carbon and environment-friendly" because bike sharing dramatically reduces air pollution and makes a significant contribution to air quality.

\subsubsection{Deficiency of Bike-sharing Platforms}

Sharing economy, namely cooperative consumption, refers to the right to use idle social resources, but sharing bicycles is associated with incremental resources invested by the platforms, rather than the existing idle resources. So it is not appropriate to easily classify bike sharing as the category of sharing economy. For example, bikes owned by platforms are all produced by their investment, and the loss or damage is afforded by themselves. But the real sharing economy is not like this. For example, through DiDi, car owners will lease their vacant rides and pay for any repair fees by themselves. Generally, unlike the light-asset operation of sharing economy, bike sharing belongs to the heavy-asset operation of leasing. The light-asset mode promotes sharing economy to provide products or services at a lower price for customers because of its low capital investment by integrating offline idle goods or services. Although sharing bicycle also provides bike rental services for customers at a lower price, the bicycles have unfavorable costs when bought and maintained.

Bike-sharing platforms earn the most of revenue from the income generated by each time a user rents a bike. Because sharing bicycles does not have rigid demand, customers' demand is likely to increase when the price is low or decreases. It is the principle of the price war among some bike-sharing platforms, keeping the price low for customers while impeding platforms to cover the costs. Therefore, increasing the frequency of bike use is the main way to earn more revenue. And increasing the number of bikes can increase the turnover of bike use because more cycles invested can raise the coverage of bikes in the cities, satisfying more user needs. It is also a great way to improve brand image and attract potential users. However, the increase of bikes and users brings original numerous bike costs and more maintenance costs due to much faulty parking or physical damage. Unfortunately, it traps platforms into profitability problems to cover the huge payments with limited revenue. Particularly in depression, heavy assets appear to be a burden on enterprises. As a typical example, OFO in the heavy-asset model produced bikes madly and experienced a high damage rate, suffering loss, and bankruptcy.

\subsubsection{Structure of Revenue And Cost of Sharing Bike Platforms}

The revenue of bike sharing platforms mainly comes from four sources, which are shown in Table 1. And the cost structure of bike sharing is shown in table 2 .

With the increase of the number of bicycles and users, the platform has more deposits for a short time, which can be understood as interest-free financing, and 
its income from advertising takes up an increasing proportion of the total income

Table 1. Structure of revenue

\begin{tabular}{|c|c|}
\hline Source of revenue & OFO (as an example) \\
\hline Income generated by each time the user rents a bike & The price of OFO is $0.5-1$ yuan per time. \\
\hline $\begin{array}{l}\text { Investment income of deposit (1)deposit before use (2) } \\
\text { prepayment deposited for the use of bicycles) }\end{array}$ & $\begin{array}{l}\text { The deposit of the OFO bike is } 99 \text { yuan, which can be taken } \\
\text { back at the end of the service but under the control of the } \\
\text { firm before refund. }\end{array}$ \\
\hline
\end{tabular}

Advertising (1)open screen advertising of bike-sharing app (2)bike-printed advertising)

Value added services based on big data

The platforms can sell personal privacy information to the corresponding businesses which will accurately push relevant information according to different users and put more accurate advertisements.

Table 2. Structure of cost

\begin{abstract}
Source of costs
Bike cost (the cost of buying or producing bicycles and putting them into use)

Maintenance, depreciation, and other operating costs of bicycles (Including material, labor and machine expense)

According to Table 1 and Table 2, increasing the number of bicycles can increase the turnover of use and thus rent income. Therefore, it is adequate to invest in bikes to expand in the early stage continuously. However, as the market becomes saturated, the average daily order volume of each bicycle and new users' growth rate lag behind the cost invested. When the turnover rate can't be increased, it will fall into a vicious circle of uncontrollable costs.
\end{abstract}

The rent and deposit income are almost the only revenue source of OFO, and their driving force of revenue mainly depends on the turnover rate. While the marginal revenue from adding a bike to increase turnover rate often fails to cover than marginal cost, per bike can not cover the unit input cost. Eventually, there is a huge flow of bicycles outsides. If the capital does not flow in constantly, sharing bike platforms will be unsustainable due to the unrecoverable loss.

\subsection{Risks And Problems}

\subsubsection{Financial Risk}

\subsubsection{High Capital Investment}

Bike sharing is a capital-intensive industry. The huge capital investment is an accessible and effective way to gain a noticeable market share when entering this industry. And it helps to form a barrier to enter and reach a monopoly status. But it will cost much to maintain and develop in the future, aggravating a heavy burden for the platform. Generally, the capital is concentrated on the purchase and maintenance of bike sharing, which is prone to cash flow problems, leading to the fracture of the capital chain. OFO's net cash flow was always negative, speeding up its bankruptcy.
Interpretation

Initial capital cost and additional investment when the platforms expand their market

Subsequent cost related to its expansion process

\subsubsection{Continuous Financing}

From the perspective of the capital source, the capital of OFO mainly came from financing. The common reason why many sharing bike platforms finance much is that revenue and initial capital are hard to cover expenses. This heavy profitability problem causes the need for new capital injection. OFO had a few retained earnings but a strategy of expanding wildly. By continuously putting bikes into the market, it can occupy the need to give an external signal that it has positive profitability, gaining the favor of the capital market and obtaining more financing. Therefore, there is such a dead cycle: crazy financing, building more bikes, financing, again. Once the market has some fluctuations and the external capital is unwilling to support sharing bicycles, the capital chain will break. The lack of capital injection eventually led to the failure of the OFO bikesharing platform. Moreover, the over-dependence on finance will harm the firm's profitability and bring the treats on the capital chain.

\subsubsection{Operational Risk}

Many sharing bike platforms like OFO regard the rent as their main revenue, but it is hard to become their core competitiveness. Because customers do not hold the loyalty of sharing bike platform, they usually have no preference among different sharing bikes, which cause the unpredictable income to a sharing bike platform and its rivals. Besides, all kinds of factors can easily influence customers' choices. For example, the rainy weather would bring fewer users, fewer turnovers, and finally, less revenue. Generally, sharing bike platforms have experienced a common and severe profitability problem in that the accesses to earnings are 
barren. It is necessary to increase their profitability channels to gain sustainable and relatively stable revenue, defending the risks from customers and other uncontrollable factors. In other words, it is the business diversification strategy that expands profitability channels and improves the total revenue of the sharing bike platform. It alleviates the existing insufficiency of profitability.

\subsubsection{Credit Risk}

\subsubsection{Misuse of Capital By Platform}

As is known to us, OFO using deposits touched the bottom line of enterprise operation, where the capital of the platform and the user's money should be strictly separated. In 2018, OFO was exposed to misappropriation of the deposit and was unable to return the deposit. It caused the majority of users to worry about the deposit in bike sharing. Hellobike adopted a different strategy than it takes Alipay's Sesame credit as a yardstick to carry out free riding. It was because of the free-use mode that OFO faced the possibility of bankruptcy.

\subsubsection{Misuse of the Facility By Customers}

Lack of public awareness and frequent uncivilized behaviors are thorny problems faced by bike sharing. Many uncivilized behaviors, such as locking the bike, or removing the electronic equipment to take it as one's own, will add bike sharing companies' spending on bike sharing maintenance.

\subsubsection{Technical Risk}

OFO bikes changed from second-hand bicycles purchased and donated to self-assembly of bicycle parts through cooperation with suppliers, enhanced by the intelligent unlocking mode and GPS positioning device. Despite the continuous improvement in the design of the bikes, such as the lightweight, there are still some deficiencies in functionality, positioning, and other settings because OFO lacked research and development ability.

\subsubsection{Social Risk}

\subsubsection{Adverse Image of Cities}

In the initial stage of development, each sharing company will choose to put in a large number of bicycles and compete blindly to get the market share. However, uneven investments also lead to an imbalance of supply and demand. In other words, some cities will face the problem of wasting or squeezing public transport resources. As a result, it influences the traffic and affects the appearance of the city.

\subsubsection{Obstacles Faced By Young And Old Users}

There are great hidden dangers in juveniles' use of sharing bikes. Juveniles themselves may not have qualified riding ability and hardly grasp the skills of observing the road and adjusting to changing circumstances. Furthermore, many teenagers have a limited understanding of traffic regulations and hence break them. In addition, it is not easy for the elderly to understand the meaning of emerging technological products. For example, they may find difficulties in downloading the platform apps, unlocking the sharing bikes, and paying for their travel expenses.

\section{DISCUSSION}

\subsection{Reduce Cost}

First of all, shared bike companies can build a platform or join a third-party platform, and present as an intermediary organ. Therefore, companies have access to individual bike owners who use their bikes at a fixed time or hardly ever use their bikes so that the idle bicycle resources of individual residents can be fully used, which will not lead to waste of resources and bicycle manufacturing costs. The platform can also recycle some second-hand vehicles for processing and reuse, to save production costs. In terms of the supervision of the platform, huge costs need to be invested, such as quantifying the user's credit and supervising it from time to time. By restricting the usable time for low-credit-score users, shared bikes can be protected, which can solve the shortage of upstream raw materials caused by the prevalence of bike sharing industry, alleviate the problem of high raw material prices caused by the shortage of raw materials, and solve the production cost of bike sharing. In this way, the platform can choose new shared services and carry out normal business activities by charging service charges. In addition, enterprises can buy their components: they only need to pay the bicycle manufacturer the assembly cost, to avoid the manufacturer buying low-cost parts for the benefit, reduce the service life of the bicycle, and avoid the virtual increase of production cost.

\subsection{Enrich the Multiple Profit Methods}

Instead of focusing on service charges, nowadays, shared bikes enterprises make their most profit on the customers' guarantee deposit, doing capital operations. However, other profitable methods can be taken into considerations. For instance, shared bikes companies can establish a short trip database that records the frequency and amount of shared bike users in different regions. Companies such as retailers would like to purchase the data to decide whether they open a new branch here. Data sales is a growing project for all 
industries, and what else bike sharing enterprises need to do is customize suitable consumption experience for customers based on big data. Also, some traditional methods such as advertisements on bikes or in their applications are feasible, and shared bike enterprises can cooperate with various industries like restaurants, retailers, and hotels, providing bundled discounts.

\subsection{Establish an Internal Supervision System}

In the bike sharing industry, once there is a deposit refund problem for users, the cost and cycle of rights protection are unbearable. Based on this, most users doubt the stability and credit of bike sharing enterprises. This is also an important reason for restricting the longterm and effective development of bike sharing. In this case, bicycle sharing enterprises should establish and improve the system of refund deposits for users, speed up the realization of "return as rent and refund as soon as possible", reduce the scale of deposit as far as possible, and prevent the formation of fund pool. Shared bikes tests can be an available way to aware users to obey parking rules. A small choice question on the application before the use of the bikes can decrease improper parking behavior. In addition, the establishment of credit ratings to distinguish customers is a significant trend. The credit score is one of the most important means of credit rating recognized by the market, which is of great significance to the development of sharing economy, including bike sharing, and this can be the reference to project the use of customers, rewarding and moderating punishment to users in holidays.

\subsection{Promote the Technological Innovation}

Shared bikes development can be verified. However, solving technical problems can be costly, especially solving them by outsourcing. Setting up technology $\mathrm{R} \& \mathrm{D}$ departments is an effective way to tackle technical problems, but it is not easy for shared bikes companies to do so because of extra costs. Hence cooperation with high technology enterprises is a tendency in bike sharing companies. The target partner can be chips companies, e-map companies, and so on. Besides, the vulnerable components of shared bikes can be manufactured from perdurable and high performance-toprice ratio materials, which can be developed by research departments and produced by shared bikes companies themselves, reducing production cost and lowering the supply pressure.

\subsection{Increase Social Publicity}

Bicycle sharing enterprises are supposed to conduct market research in advance, make strategic planning and expand production reasonably. The customers of bike sharing are the general public. Enterprises can develop their software or cooperate with the platform, and attach themselves to the virtual world, so that bike sharing can connect with the virtual social circle, which increases user engagement. Users can communicate in the social circle, enhance the social experience among bike sharing users, and increase the popularity of bike sharing. Like a certain game, the platform can also add more humanized virtual area division, broadcast relevant news headlines daily, and what is important is the advertisements of the "bike properly and park properly" slogan in this virtual social circle. Users imperceptibly enhance the identity of bike sharing and have a brand preference, which contributes to profits and bike protection. At the same time, bike sharing enterprises win brand value through value-added services. As for different user groups, special tutorials and bikes can be launched to provide help and services, which is beneficial to establish a brand image.

\section{CONCLUSION}

In conclusion, this study mainly focuses on what is shared bikes. The bike-sharing is an "Internet plus" rental economy, how the shared bikes work and how many benefits the shared bikes can provide the society. Such as protect air quality, avoid traffic jams and bring convenient travel modes for users. Then we analyze some methods that how the bike-sharing platform gains revenue. It presents four methods: income earned after each use, collecting the deposit from the user, advertising for shared bikes, for better sales, and relies on big data to capture users' personal information and sell it to other platforms. The cost structure includes bike cost, platform initial asset cost, additional investment, and bike repair costs. Then this research finds and analyzes the various risk problems that bikesharing will face in today's society. Like finds and explains the financial risk, the poor profitability, the credit risks arising from the bottom line of business operations, the technical problems of bicycles themselves, and the blind competition in the early days of bike-sharing, have harmed society, this phenomenon creates a social risk problem. And provide some useful methods to solve these risk problems. They reduce costs, implement various profit-making schemes, establish an internal supervision system, develop technology for bicycles, and carry out social publicity.

The limitation of this study is that we use secondhand data in the analysis, and do not get the first-hand data through the field survey to conduct research. In future studies, the researchers can add primary data through field research to make the findings more reliable.

\section{REFERENCES}

[1] Fanaee-T, Hadi, and Gama, Joao, 'Event labeling combining ensemble detectors and background 
knowledge', Progress in Artificial Intelligence, Springer Berlin Heidelberg, 2013, pp. 1-15.

[2] Meddin, Russell, and Paul DeMaio. The bikesharing world map, 2016, URL: http://www. metrobike. net.

[3] Felson, M., Spaeth, J.L. Community structure and collaborative consumption:a routine activity approach. Am. Behav. Sci. 21 (4), (1978), 614-624.

[4] Zhu X, Liu K. A systematic review and future directions of the sharing economy: business models, operational insights and environmentbased utilities[J]. Journal of Cleaner Production, 2020.

[5] Kabra, A., Belavina, E., Girotra, K. Bike-share Systems: Accessibility and Availability, Chicago Booth Research Paper, 2016.

[6] Kaspi, M., Raviv, T., Tzur, M. Detection of unusable bicycles in bike-sharing systems. Omega 65, 2016, pp. 10-16.

[7] Kaspi M, Raviv T, Tzur M., Bike-sharing systems: user dissatisfaction in the presence of unusable bicycles. IISE Transactions, 49(2), 2017, pp. 144158.

[8] Pal A, Zhang Y., Free-floating bike sharing: solving real-life large-scale static rebalancing problems. Transport. Res. C Emerg. Technol. 80, 2017, pp. 92-116.

[9] Angeloudis P, Hu J, Bell M.G., A strategic repositioning algorithm for bicycle-sharing schemes. Transportmetrica: Transport. Sci. 10 (8) (2014) 759-774.

[10] Chen Y, Wang D, Chen K, et al. Optimal pricing and availability strategy of a bike-sharing firm with time-sensitive customers[J]. Journal of Cleaner Production, 2019, 228: 208-221.

[11] Tranfield D, Denyer D, Smart P, Towards a methodology for developing evidence-informed management knowledge by means of systematic review. British Journal of Management, 14(3), (2003), 207-222.

[12] https://en.wikipedia.org/wiki/Case_study. 